\title{
MATHS ANXIETY: FURTHER COMPLICATED BY SPREADSHEET SHOCK?
}

\author{
Joanne Smailes ${ }^{1}$, \& Carlos Fresneda-Portillo ${ }^{2}$ \\ ${ }^{1}$ Faculty of Business and Law, University of Northumbria (United Kingdom) \\ ${ }^{2}$ School of Engineering, Computing and Mathematics, Oxford Brookes University (United Kingdom)
}

\begin{abstract}
This paper offers an augmentation to the work of Smailes and Heyman (2018) and Farjadpour and Fresneda-Portillo (2018). Smailes and Heyman (2018) considered techniques for teaching mathematics to non-mathematicians (e.g. business programmes) whilst Farjadpour and Fresneda-Portillo (2018) considered mathematics anxiety. What was particularly salient about the latter study was that it involved undergraduate mathematics students. This struck a particular chord with the first presenter: if mathematics anxiety occurred in students choosing this as a specialism, what additional impacts could be occurring within Business based cohorts? Are there further complexities that require consideration within these cohorts? For example, past experience indicates that the advent of technologies, in this case spreadsheets, can be both a blessing and a curse. Hesse and Hesse-Scerno (2009) posit that spreadsheets have changed the world and suggest that they have potentially saved some mathematics based business curricula. Spreadsheets are now a universal business tool that needs to be learned (Pan et al., 2018). What are the potential relationships between mathematics anxiety and spreadsheet confidence? Do similar factors that impact on mathematics anxiety impact on spreadsheet confidence? This paper illustrates that indeed there are a number of similarities between the two and suggest the impact of technologies is such that techno-math literacies supersedes numeracy capability as a concept (Geiger, Goos, \& Forgasz, 2015). Furthermore, additional dynamics linked to confidence are exposed that merit further qualitative investigation.
\end{abstract}

Keywords: Mathematics anxiety, perceived study abilities, technology impact, higher education.

\section{Introduction}

A lack of confidence in learning mathematics is a long-standing phenomenon. It is now almost 50 years since Richardson and Suinn (1972) designed an instrument for the measurement of mathematics anxiety which in both its original and adapted formats is still commonly utilized today.

Pelch (2018) acknowledges that mathematics anxiety is a difficult area of research due to the multiplicity of interrelated factors involved. Investigations within the literature include examinations of what may occur in early and later stages of schooling, demographic and geographic influences, links to self-efficacy and the impact of technology to name just some of the areas of interest. For example, Farjadpour and Fresneda-Portillo (2018) used an adapted Mathematics Anxiety Scale to assess the impact of gender, ethnicity, parental support in mathematics, number of siblings amongst other factors.

The lack of a mathematical skills base, often referred to as mathematics literacy continues to be a global issue due to the impact in the economy of a country (Geiger et al., 2015; Johnson, 2012; Matthews, Hodgson, \& Varsavsky, 2013; Deloitte 2013). However, due to the exponential growth of information technologies, in particular, of mobile technologies, it is proposed that mathematical literacy can no longer be treated separately. Geiger et al. (2015) recommends techno-maths literacy as a more appropriate nomenclature.

The authors would argue that this is particularly case within higher education. Evidence from employers backs this up. Grant, Malloy, and Murphy (2009) noting that within business IT abilities are as "customary as pen and paper" (p.145). It is clear that the most common IT ability associated with mathematics is spreadsheet use and preferred over specialist statistics software (Pan et al., 2018; Brennan \& Vos, 2013; Johnson, 2012).

The advances in technology have also changed the landscape of employer expectations. For example, data analysis once considered a specialism is now viewed as a generalist function involving spreadsheet skills is implied (Tufte, 2004). 
In this context, a module, known as Business Analysis, is the main mathematical component delivered to all (approximately 800 students, 400 per semester) undergraduate Business and Management programmes. This unique combination of confidence in both mathematics and spreadsheet use are known issues of interest. Mathematics anxiety is a well-established factor, and the teaching strategies employed are continually practised and reviewed in an attempt to minimise impact of student learning, e.g. flipped classroom methodology (Smailes \& Heyman, 2018).

As documented by Verhoeven, Heerwegh, and De Wit (2016) IT capabilities of students are not as anticipated. Although many students have used a spreadsheet, their previous experience is basic and appears to be limited to data entry, basic formulas and perhaps graphical construction. In the very early stages of teaching there is a sense that mathematics anxiety is exacerbated by spreadsheet shock. This latter point also being picked up by Gorman (2008) whom comments that the necessity to learn Excel can become an additional obstacle in learning statistics - the vast majority of the business analysis curriculum.

Spreadsheet shock is a self-generated term used to express how many students, claim to be familiar with spreadsheets but within two to three weeks of teaching, realize how little they actually know, or that they may incorrectly assumed was simple. A common example of the latter is that many students find that constructing a graph from scratch is more complex than previously led to believe.

The most notable issue in considering both mathematical and spreadsheet confidence is the influence of gender. This factor provides a focus to several investigations, the majority of which, note how females report lower levels of confidence in both than males (Pelch, 2018; Nunez-Pena, Suarez-Pellicioni, \& Bono, 2016; Verhoeven et al., 2016; Plenty \& Huebeck, 2013; Tarasi, Wilson, Puri, \& Divine, 2012; Joyce, Hassall, Montano, \& Anes, 2006). As noted by Matthews et al. (2013) amongst others this element is well researched due to its impact on both enrolment and retention within Science, Technology, Engineering and Mathematics (STEM) subjects.

This paper aims to extend research by Farjadpour and Fresneda-Portillo (2018) by considering a sample of business and management undergraduate students and determine factors impacting both mathematics anxiety and spreadsheet confidence.

\section{Methodology}

A questionnaire was distributed to business and management students shortly before the commencement of the teaching programme. Fourteen questions employed by Farjadpour \& Fresneda-Portillo (2018) were adapted slightly to take in account the context of the business and management curriculum. Six supplementary questions were included referring to spreadsheet knowledge. An additional section of ten questions was added to in respect to self-efficacy (Bandura, 2006) - a seminal author in this field. As recommended by Bandura (2006), for all mathematical, spreadsheet and self-efficacy questions the traditional Likert scale was replaced by a wider numerical scale, in this case a percentage level of confidence, where 0 indicated no confidence through to 100 full confidence. An extra Likert based question was included on how anxious facing an exam would as anxiety is an known entity that can be independent from mathematics and/or spreadsheet confidence (Pekrun, Goetz, Titz, \& Perry, 2002). As noted by Farjadpour \& Fresneda-Portillo (2018), there are a number of demographic sensitivities which need to be considered when collecting data, therefore any questions relating to demographic elements such as parents, siblings, mathematical support mechanisms were carefully designed to take any sensitivities into account.

\section{Results and analysis}

University attendance recording systems indicated that there were 382 students registered in semester 1, 147 responses were received yielding a 38.5\% response rate. Responses rates from gender and nationality broadly represented the student population. The variable of interest, spreadsheet confidence is an average of the six questions presented within the questionnaire. The mean for the whole sample was $\mu=56.75$ and the standard deviation $\sigma=22.78$. Sample skewness was found to be -0.013 and the kurtosis -0.769 . Furthermore, the median is 57.80 , very close to the mean and implies that the distribution is symmetrical. After studying the Q-Q plot which additionally suggested that the variable spreadsheet confidence is normally distributed, and thus, the mean and standard deviation are representative parameters of the sample.

The main factors to be investigated alongside spreadsheet confidence were self-efficacy, mathematics anxiety and test anxiety. The latter factor was ranked, and maths anxiety sample results cannot be deemed as following the normal distribution. As a consequence, non-parametric statistics are applied from now on. Firstly, the Spearman's correlation coefficient is applied to test the null hypothesis of monotonic (the more of one variable, the more of the other and vice versa) relationship between variables (Table 1). 
Table 1. Non-Parametric correlations $(n=147)$.

\begin{tabular}{crcc}
\hline & $\begin{array}{c}\text { Spreadsheet } \\
\text { Confidence }\end{array}$ & Mathematics Anxiety & Self-Efficacy \\
\hline Mathematics Anxiety & $0.559^{* * * *}$ & & \\
Self-Efficacy & $0.274^{* *}$ & $0.384^{* * * *}$ & \\
Test Anxiety & $0.442^{* * *}$ & $0.491^{* * *}$ & 0.145 \\
\hline${ }^{*} \mathrm{p}<0.05, * * \mathrm{p}<0.01, * * * \mathrm{p}<0.001$ & &
\end{tabular}

Table 1 illustrates all the variables of interest preserve a monotonic increasing relationship except for Test Anxiety and Self-Efficacy. The relationship between Mathematics Anxiety and Spreadsheet Confidence as well as with Test Anxiety are confirmed. On the other hand, Self-Efficacy is significantly correlated with both Spreadsheet Confidence and Mathematics Anxiety but not with Test Anxiety.

The null hypothesis linked to gender (i.e. no differences between males and females) was tested using the non-parametric test for independent samples (Mann Whitney) was applied to Spreadsheet confidence, Mathematics Anxiety, Self-Efficacy and Test Anxiety (Table 2).

Table 2. Mann Whitney test-Factor: Gender $(n=147)$.

\begin{tabular}{cccccc}
\hline & Mann Whitney U & Z & p-value & $\begin{array}{c}\text { Median } \\
\text { Males }\end{array}$ & $\begin{array}{c}\text { Median } \\
\text { Females }\end{array}$ \\
\hline Spreadsheet Confidence* & 1978.5 & -2.411 & .016 & 62.92 & 50 \\
Mathematics Anxiety* & 1972 & -2.437 & .015 & 79.32 & 72.71 \\
Self-Efficacy & 2202 & -1.520 & .129 & 69.15 & 73 \\
Test Anxiety** & 1783.5 & -3.320 & .001 & 3 & 2 \\
\hline *p & & & & &
\end{tabular}

$* \mathrm{p}<0.05, * * \mathrm{p}<0.01, * * * \mathrm{p}<0.001$

Table 2 demonstrates that there is a significant difference between males and females in respect to Mathematics Anxiety, Spreadsheet Confidence and Test Anxiety. In all three cases, males exhibit higher levels of confidence.

Farjadpour \& Fresneda-Portillo, (2018) established a relationship between the number of siblings and mathematics anxiety and hence was examined within the business and management cohort. To assess this the sample was divided into two groups. Group A respondents whom had two siblings or less and Group B defined as those with three siblings or more (Table 3).

Table 3. Mann Whitney test - Factor: 3 or more siblings $(n=147)$.

\begin{tabular}{lccccc} 
& Mann Whitney U & Z & p-value & $\begin{array}{r}\text { Median } \\
\text { Group A }\end{array}$ & $\begin{array}{c}\text { Median } \\
\text { Group B }\end{array}$ \\
\hline Spreadsheet Confidence & 1800.5 & -.889 & .374 & 60.83 & 52.75 \\
Mathematics Anxiety* & 1561 & -1.983 & .047 & 79.14 & 70.75 \\
Self-Efficacy** & 1352 & -2.939 & .003 & 72.50 & 64.60 \\
Anxiety** & 1380 & -2.924 & .003 & 3 & 2 \\
\hline * $<0.05, * * \mathrm{p}<0.01, * * * \mathrm{p}<0.001$ & & & & &
\end{tabular}

Table 3 determines that there is a significant difference between Group A and Group B in regards to Mathematics Anxiety scores, Self-Efficacy and also on Test Anxiety. In all cases, the scores of Group A are higher than those scores on Group B. The results imply that students with two or less siblings feel less Mathematics Anxiety, have higher levels of Self-Efficacy and are less anxious in respects to test situations. 


\section{Conclusion}

In line with the mathematics and engineering cohort there are distinct gender differences in respect to mathematical anxiety. Evidence from the business and management cohort suggests that this also extends into test anxiety and spreadsheet confidence where males illustrate higher levels of confidence than females. However, there is not enough evidence to suggest that gender differences occur in respect to reported self-efficacy. Findings in respect to the number of siblings do not concur with the mathematics and engineering cohort, it is indicated that for business and management students children from larger families (three or more siblings) have lower levels of mathematical confidence and self-efficacy. This does not appear to be the case in relation to spreadsheet confidence.

Connections were established between the four factors of particular interest i.e. self-efficacy, test and mathematics anxiety and spreadsheet confidence. In general levels of spreadsheet confidence were much lower than that of mathematics and levels of self-efficacy. In all permutations there were positive correlations found e.g. the more confident a person exhibited in mathematics the higher their spreadsheet confidence was and vice versa. Overall, there is an indication that as suggested by Geiger et al. (2015) educators need to consider both factors in unison i.e. techno-mathematics. The findings reveal additional potential links to self-efficacy. There is an intention to implement a further qualitative research strand to scrutinise the interrelationships between techno-maths literacy, self-efficacy, gender and family size from a more personal perspective.

\section{References}

Bandura, A. (2006). Guide for constructing self-efficacy scales. In T. Urdan \& F. Pajares (Eds.), Self-efficacy Beliefs of Adolescents (pp. 307-337): Information Age Publishing

Brennan, R., \& Vos, L. (2013). Effects of Participation in a Simulation Game on Marketing Students' Numeracy and Financial Skills. Journal of Marketing Education, 35(3), 259-270. doi: $10.1177 / 0273475313482928$

Deloitte (2013) Measuring the Economic Benefits of Mathematical Science Research in the UK, Engineering and Physical Sciences Research Council and The Council of the Mathematical Sciences.

Farjadpour, M., \& Fresneda-Portillo, C. (2018). A statistical analysis of the factors influencing mathematics anxiety in undergraduate students of mathematics and engineering. Paper presented at the International Conference on Education and New Developments Budapest, Hungary 23 to 25 June.

Geiger, V., Goos, M., \& Forgasz, H. (2015). A rich interpretation of numeracy for the 21st century: a survey of the state of the field. ZDM Mathematics Education, 47, 531-548. doi:10.1007/s11858-015-07081

Gorman, M. F. (2008). Evaluating the Integration of Technology into Business Statistics. INFORMS Transactions on Education, 9(1), 10-19.

Grant, D. M., Malloy, A. D., \& Murphy, M. C. (2009). A Comparison of Student Perceptions of their Computer Skills to their Actual Abilities. Journal of Information Technology Education, 8, 141-160.

Hesse, R., \& Hesse-Scerno, D. (2009). How Electronic Spreadsheets Changed the World. Informs, 39(2), 159-167.

Johnson, L. (2012). Closing the Loop: Using Assessment Results to Modify the Curriculum So That Student Quantitative Reasoning Skills Are Enhanced. American Journal of Business Education, 5(4), 465-468.

Joyce, J., Hassall, T., Montano, J. L. A., \& Anes, J. A. D. (2006). Communication apprehension and maths anxiety as barriers to communication and numeracy skills development in accounting and business education. Education + Training, 48(6), 454-464. doi: https://doi.org/10.1108/00400910610692967

Matthews, K. E., Hodgson, Y., \& Varsavsky, C. (2013). Factors influencing students' perceptions of their quantitative skills. International Journal of Mathematical Education in Science and Technology, 44(6), 782-795. doi:10.1080/0020739X.2013.814814

Nunez-Pena, M. I., Suarez-Pellicioni, M., \& Bono, R. (2016). Gender differences in test anxiety and their impact on higher education students' academic achievement. Procedia - Social and Behavioral Sciences, 228, 154-160.

Pan, K., Blankley, A. I., Mazzei, M. J., Frownfelter Lohrke, C., Marshall, J. B., \& Carson, C. M. (2018). Surveying industry advisors to select data analytics topics for all business majors. The International Journal of Management Education, 16, 483-492.

Pekrun, R., Goetz, T., Titz, W., \& Perry, R. P. (2002). Academic emotions in students' self-regulated learning and achievement: A program of quantitative and qualitative research. Educational Psychologist, 37, 91-106. 
Pelch, M. (2018). Gendered differences in academic emotions and their implications for student success in STEM. International Journal of STEM Education, 5(33), 1-15.

Plenty, S., \& Huebeck, B. G. (2013). A multidimensional analysis of changes in mathematics motivation and engagement during high school. Educational Psychology, 33(1), 14-30. doi:10.1080/01443410.2012.740199

Richardson, F. C., \& Suinn, R. M. (1972). The Mathematics Anxiety Rating Scale: Psychometric data. Journal of counseling psychology, 19(6), 551-554.

Smailes, J., \& Heyman, A. (2018). Lectures, Attendance and Engagement: Can we reverse the decline? Paper presented at the International Conference on Education and New Developments Budapest, Hungary. 23 to 25 June 2018

Tarasi, C. O., Wilson, J. H., Puri, C., \& Divine, R. L. (2012). Affinity for Quantitative Tools: Undergraduate Marketing Students Moving Beyond Quantitative Anxiety. Journal of marketing education, 35(1), 41-53. doi:10.1177/0273475312460764

Tufte, D. (2004). A New and Different Spreadsheet Text the Art of Modeling with Spreadsheets: Management Science, Spreadsheet Engineering and Modeling Craft by Stephen

Powell, G. \& Baker, K. R. INFORMS Transactions on Education, 4(3), 69-73. doi:https://doi.org/10.1287/ited.4.3.69

Verhoeven, J. C., Heerwegh, D., \& De Wit, K. (2016). ICT learning experience and research orientation as predictors of ICT skills and the ICT use of university students. Educational Information Technology, 21, 71-203. doi:10.1007/s10639-014-9310-3 